\title{
Agent-based modelling to predict policy outcomes: a food waste recycling example
}

\author{
A.C. Skeldon ${ }^{1 *}$, F. Schiller ${ }^{2}$, A. Yang ${ }^{3}$, \\ T. Balke-Visser ${ }^{4}$, A. Penn ${ }^{5}$, N. Gilbert ${ }^{5}$ \\ 1 Department of Mathematics, University of Surrey, Guildford, Surrey, GU2 7XH, \\ 2 Handyurbansolutions, Handyurbansolutions.com, Hanover, \\ 3 Department of Engineering Science, University of Oxford, Oxford, OX1 3PJ, \\ 4 Vanderlande Industries, 5466 RB Veghel, Netherlands, \\ 5 Department of Sociology, University of Surrey, Guildford, Surrey, GU2 7XH. \\ * Corresponding author
}

May 14, 2018

\begin{abstract}
Optimising policy choices to steer social/economic systems efficiently towards desirable outcomes is challenging. The inter-dependent nature of many elements of society and the economy means that policies designed to promote one particular aspect often have secondary, unintended, effects. In order to make rational decisions, methodologies and tools to assist the development of intuition in this complex world are needed. One approach is the use of agent-based models. These have the ability to capture essential features and interactions and predict outcomes in a way that is not readily achievable through either equations or words alone.

In this paper we illustrate how agent-based models can be used in a policy setting by using an example drawn from the biowaste industry. This example describes the growth of in-vessel composting and anaerobic digestion to reduce food waste going to landfill in response to policies in the form of taxes and financial incentives. The fundamentally dynamic nature of an agent-based modelling approach is used to demonstrate that
\end{abstract}


policy outcomes depend not just on current policy levels but also on the historical path taken.

keywords Agent-based modelling; biowaste policy; path-dependency; landfill tax; renewable obligation certificates

\section{Background}

Designing effective policy to manage social systems is a difficult problem. Many systems are complicated and nonlinear, which can result in indirect, unforeseen, effects of a policy. The behaviour may be non-intuitive: the same policy applied in apparently similar scenarios may have different effects due to historical factors. This is known as path dependency. These system issues can be further exacerbated by the fact that different policy levers coming from different policy perspectives are frequently aimed at steering the same system. For example, at the UK government level, the Department structure lends itself to policy design in silos, with each Department championing their own policies with their own objectives and in competition with each other for financial resources from the Treasury.

In this paper we illustrate how agent-based modelling can be used for scenario planning and enable the user to investigate how policy decisions made at a macro level impact on behaviour at the micro level, which in turn produces emergent macro level outcomes. In contrast to other modelling approaches, agent-based models (ABMs) are not expressed in terms of variables, functions or equations $[1,2]$. Instead the building blocks of an ABM are autonomous heterogeneous entities (so-called agents) that interact with each other and with an artificial environment [3, 4]. For example, agents could be households, consumers, companies, workers or even whole nations. Repeated interactions among these agents over time induce ceaselessly changing microeconomic patterns (e.g. production and consumption levels). The goal of ABMs is to properly describe complex systems and to infer and analyse their aggregate propertiesin a bottom-up perspective - from the interactions and behaviours of micro entities [2].

ABMs have been used in some policy areas, for example in economic policy 
[5] but are still not widely used in others [6]. Here, we focus on the area of policy for food waste disposal within the UK, but the key message that policy outcomes can be path dependent and that dynamical modelling should be an important part of the planning process, holds more generally.

The last two decades have seen a significant reduction in the percentage of waste sent to landfill sites due to policy interventions, with more recycling of paper, glass and metal and more biodegradable waste directed to either composting or anaerobic digestion. The principal responsibility for waste policy lies with Department for Environment, Food and Rural Affairs (DEFRA), but some aspects of environmental governance are also managed from the Department for Energy and Climate Change (DECC), which was subsumed within the new Department of Business, Energy and Industrial Strategy (BEIS) in 2016. Reducing the quantity of biodegradable waste sent to landfill and the concomitant development of a market for renewable energy from biodegradable waste requires the coordination of many agencies in both Departments [7], yet until the joint publication of the Anaerobic Digestion Strategy and Action Plan in 2011 [8], there was little clear evidence of a joint strategy.

Waste policy developed due to concerns over the capacity of landfill sites in the UK in 1990s [9] which led to the Department of the Environment strategy document "Making Waste Work: A National Strategy for Waste" [10]. This was a precursor of similar concerns in the European Community (EC) over capacity and other possible negative effects of landfill on the environment, specifically surface water, groundwater, soil, air and human health, which led to the Landfill Directive [11]. This Directive set out requirements that member states reduce the amount of biodegradable municipal waste going to landfill, with specific targets for the UK set at $75 \%$ of the 1995 level by 2011, 50\% by 2013 and $33 \%$ by 2020 .

In order to meet the objective of decreasing the amount of waste sent to landfill, the UK introduced the 1996 UK Landfill Tax, heralded as the UK's first environmental tax. The tax is levied on landfill site operators and collected by HM Customs and Revenue and is charged per tonne of waste. There are two levels, one for inert waste and one for active waste, where biodegradable waste, including food waste, is classified as active waste. Landfill site operators pass the Landfill Tax on to waste producers as part of the so-called gate fee, which is the charge that landfill site operators make for taking waste based, literally, 
on the number of tonnes of waste that come through the site gate. For active waste, Landfill Tax was initially introduced at the low level of $£ 7$ per tonne, but has been ramped up by successive governments to its current level in April 2018 of $£ 88.95$ per tonne, see Figure 1. The Landfill Tax provides an incentive for waste producers to reduce the amount of waste that they send to landfill and is used as a policy lever to enable the UK to meet its EU landfill targets.

Along with concerns over capacity, biodegradable waste regulation has also been driven by growing concerns over climate change. Methane, a potent greenhouse gas, is released during the decomposition of biodegradable waste in landfill sites [12]. Methane emission from landfill sites and carbon emissions in the sup-

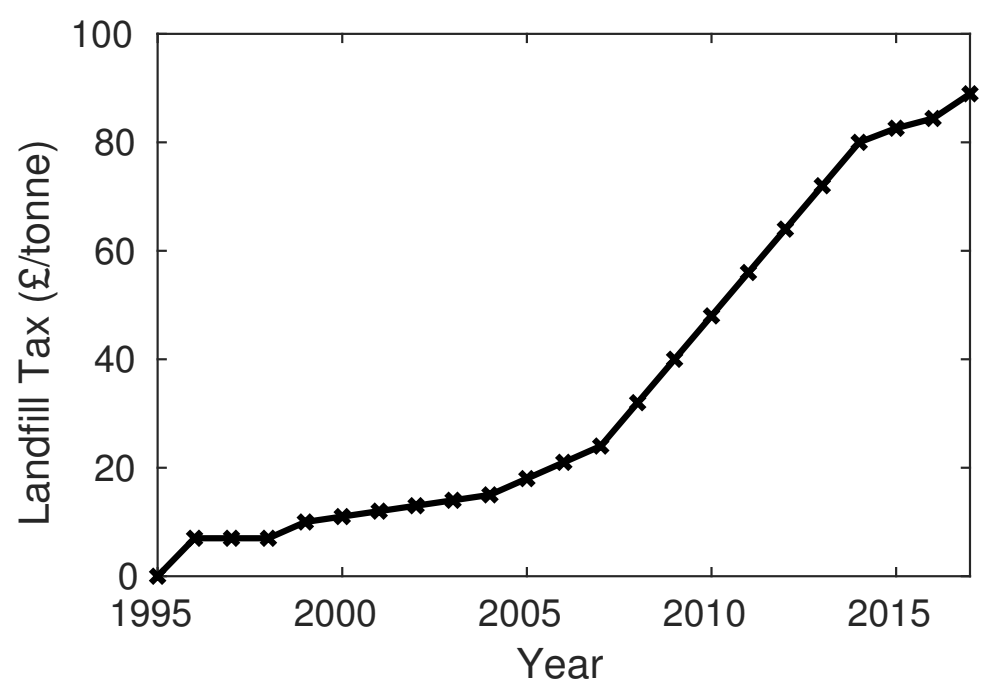

Figure 1: UK Landfill Tax from 1995-2017.

ply chain resulted in the DEFRA Review of Waste Policy in England (2011) identifying food waste as a priority [13]. This was followed up by the Anaerobic Digestion Strategy and Action Plan (2011), under which anaerobic digestion (AD) was promoted as an efficient use of biodegradable waste.

Hence, from a DEFRA perspective, the main focus has been on reducing the amount of biodegradable waste sent to landfill, initially driven by concerns over capacity and subsequently by concerns over greenhouse gas emission from landfill sites. They have used, and continue to use, Landfill Tax as one of their main policy instruments. 
At the same time, concern over climate change has changed energy policy. Under the 2008 Climate Change Act [14] the UK aims to reduce greenhouse gas emissions by at least $80 \%$ of the 1990 levels by 2050. Recognising that an important element of greenhouse gas emissions comes from the reliance on fossil fuels, the Renewable Obligation (RO) was introduced by the UK government in 2002 and reformed in 2009 [15]. The RO requires energy producers to provide a particular share of their energy from renewable sources to their customers. To support this, electricity generators receive Renewable Obligation Certificates (ROCs) for 'green electricity', that is electricity produced from renewable sources. ROCs give electricity generators a price for green electricity that is above the wholesale market price for electricity. ROCs are reviewed every four years, with different technologies being allocated a different level of ROCs per MWh of electricity generated [15] according to their technological and economic development. As a consequence, ROCs received for individual renewable energy technologies can change stepwise over time.

The decomposition of biodegradable waste in AD plants produces methane that can either be sold directly as a renewable fuel or burned on-site to generate green electricity. Either way, an important income stream for AD plants comes from ROCs. The net effect is that the waste policy of promoting the use of AD plants is intimately connected with the energy policy of using ROCs, with ROCs having a direct impact on the financial viability of AD plants.

Using an agent-based model we consider a number of different scenarios to examine the impact of Landfill Tax and the RO policy. This highlights how the impact of policies on the development of an AD industry is path dependent, that is, how the outcome of a policy is dependent both on the nature of the policy and the length of time that a policy is in place. In Section 2 we give a short introduction to the agent-based model and the software used to create, run and analyse model output. This is followed by key results and discussion in Sections 3 and 4, respectively. 


\section{The agent-based model and the computa- tional approach}

\subsection{The agent-based model}

The specific model considered here illustrates the possible impact of Landfill Tax and ROCs on the recycling of food waste. In the model, the agents consist of individual companies that either produce food waste or take food waste in as a raw material and process it; this latter category of agents includes in-vessel composters and AD plants which currently represent the prime methods used for recycling food waste. In-vessel composting refers to a collection of methods where organic waste is recycled in a container or building in which air circulation, temperature and moisture are controlled to ensure that decomposition occurs aerobically. Conversely, in AD plants decomposition is designed to occur without access to oxygen, resulting in the production of methane. AD plants are more expensive to both build and run than in-vessel composters.

Most of the simulations shown below start with no waste processing agents and with all organic waste going to landfill. Waste processing agents start up if it is 'profitable' for them to do so, and go out of business if they go bankrupt. Each day, each agent runs through a sequence of steps that mimics the day-today decision processes of the companies concerned. For example, producers of food waste generate waste and send their waste to composters, AD plants or to landfill, whereas, waste processing companies take in food waste, process it and sell the products, debts are paid and money received for sale of the outputs.

Each agent develops its own trading network: waste processing agents start by only having a few business 'contacts' and gradually extend their list of contacts with time. This knowledge network is important: an agent can only do business with someone that they know.

The overall daily list of decisions for the agents is set out in Table 1. Each of these decisions have to be modelled. So for example, specific rules have to be defined for how waste processing companies decide to start up; who trades 


\begin{tabular}{|l|l|}
\hline 1. & Agents that produce food waste buy raw materials. \\
3. & The raw materials are processed, generating food waste. \\
4. & New contracts are made and food waste transferred under the terms of \\
& these contracts from suppliers to waste processors. \\
5. & Prices of food waste are updated by the suppliers of food waste. \\
6. & Any food waste that has not gone to food waste processors goes to landfill. \\
7. & Waste processors buy any additional materials that they need to process \\
8. & the waste that they have. \\
9. & Waste is processed by the waste processors. \\
10. & Waste processors pay for operating costs and for loans. \\
11. & The profit for each agent is calculated. \\
12. & Any agents who have run out of money go bust. \\
13. & New 'contacts' are made. \\
14. & New waste processing companies are formed if it is 'profitable' for them \\
15. & to do so. \\
\hline
\end{tabular}

Table 1: List of daily tasks in the agent-based model.

with whom; how waste is priced and how different policies are implemented. Full details of the model, model parameter choices and how these decisions are implemented are given in the Supplementary Material.

\subsection{The computational method and agent-based software}

During the model development phase, the model was coded in an open source agent-based modelling package called Netlogo [16] (version 5.0.5). The Netlogo environment has the advantage that it is easy to construct interactive models, where the user can vary parameters using buttons or sliders and consequent model behaviour can be observed, in real time, in a variety of graphical forms.

Subsequently, for speed of computation and ease of analysis of the simulation data, the model was re-coded in MATLAB [17]. Both the Netlogo code and the MATLAB code are available from the Surrey Data repository. 


\section{Results}

In section 3.1, we discuss two general scenarios (i) the impact of ramping up the Landfill Tax in the absence of ROCs; (ii) the impact of ramping the Landfill Tax with different levels of ROCs. The results demonstrate how different policies differentially affect AD plants and in-vessel composters and how existing policy has favoured the development of AD plants at the cost of in-vessel composting. This viewpoint is supported by data showing the number of AD plants versus in-vessel composters for the period 2009-2016.

Looking ahead, there are various policy options open to DEFRA and BEIS for incentivising the bio-waste industry. In section 3.2, we demonstrate that, even with only two policies, the outcome can depend on how the policies are applied: the same levels of Landfill Tax and ROCs can result in radically different proportions of $\mathrm{AD}$ plants to in-vessel composters depending on the order and the time for which the policies are implemented.

\subsection{Changing Landfill Tax and ROCs}

Before considering how a changing policy landscape alters policy outcome, the basic behaviour of the model is shown. In Figure 2, the result of a typical simulation with the landfill gate fee fixed at $£ 20$ ( $£ 20$ is the typical landfill operating cost excluding Landfill Tax) and no ROCs is shown. Over time, as seen in (a), the amount of food waste going to landfill reduces, in parallel the number of companies that take in food waste grows and the price goes up (see (b)). However, there are a number of important points to note. 


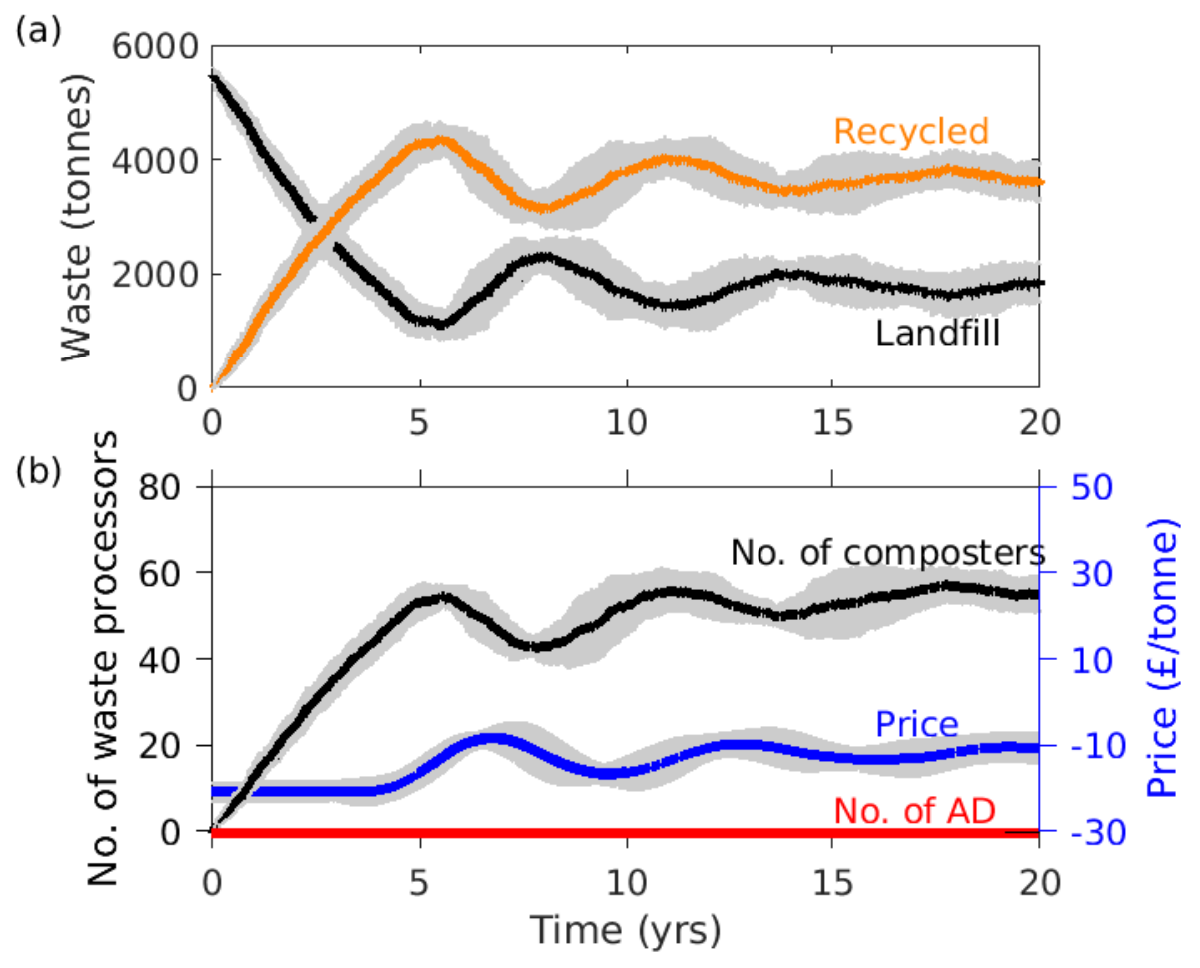

Figure 2: Typical model behaviour with a gate fee of $£ 20$ (no Landfill Tax) and no ROCs. (a) Shows how the amount of waste going to landfill (black), on average, decreases with time settling to an approximately constant level. The reduction in waste going to landfill is mirrored by an increase in waste that is recycled (orange). (b) The corresponding changes in the number of composters (black) and in the price of waste (blue). No AD plants (red) are set up because the conditions are not favourable for their establishment. The 'price' is negative, indicating that waste producers have to pay to have their organic waste removed. In all cases, the lines shown are the average for 10 simulations. The grey band indicates the mean plus/minus one standard deviation. 
Firstly, over time, the amount of food waste going to landfill settles down to an approximately constant, non-zero, value. This is a direct result of the marketdriven price dynamics within the model: companies producing food waste set higher prices if they are able to sell all their food waste to waste processing companies, and decrease their prices if they have to send some of it to landfill. Implicit within this decision rule is that companies only adjust their prices through what they learn about the market through their interactions; there is no global price information. The average price across all companies reaches an approximate equilibrium, with some companies increasing their prices and some decreasing their prices, at the point when the average increase in price is equal to the average decrease in price. For a total of $N$ companies, if $p$ of them recycle their waste and increase their price by $u$, then there are $(N-p)$ companies who send some waste to landfill and decrease their prices by $d$. An estimate for the equilibrium level is $p u=(N-p) d$, which gives that the fraction of food waste producers that recycle their waste is approximately $\frac{p}{N}=\frac{d}{u+d}$. For the simulation shown in Figure $2, u=0.05, d=0.1$, leading to approximately two-thirds of waste being diverted from landfill. We note that the power of the agent-based modelling approach is its ability to investigate the non-equilibrium situation: in a setting such as that considered here, where there is no global price information and the timescales for market change are relatively long, it is questionable whether equilibrium is reached before either a policy change or technical advance occurs.

Secondly, as more waste processing companies enter the marketplace there is competition for waste, so the average price increases from the initial value of $-£ 20$ that is fixed by the gate fee. (Note that we have defined the 'price' to be the amount of money received by the waste producer for organic waste in pounds per tonne. Hence a negative price means that waste producers have to pay for the removal of their organic waste, rather than being able to sell it.) Prices do not increase indefinitely. Waste processing companies start out with an initial investment of capital and at each time step spend money on raw materials, operating costs and loan repayment. At the same time they receive an income from the sale of their products. Although the initial investment enables companies to operate for the short term even if they make a loss, they cannot keep making a loss without running out of money and consequently going out of business. Within the ABM simulations, the result is that prices settle about an equilibrium value where on average companies just make a 
profit. For composters, with the parameters fixed as given in Table S1 in the Supplementary Material, this means that the maximum sustainable 'price' for organic waste is approximately $-£ 12$.

Thirdly, there is initially an approximately linear increase in the number of composters. In the model, we set how frequently new companies consider whether to start up or not. Here set to one per fortnight, companies only set up if it is economically attractive to do so. Since initially the price is low, companies set up at a constant rate of one per fortnight, resulting in the linear increase in the number of companies.

Finally, there are large oscillations in the price, which then lead to large oscillations in the number of waste processing companies and consequently in the amount of waste going to landfill. The presence of oscillations is because there is inherently some delay in the system: when waste is very low in price, companies make a profit. This accrued wealth then sustains them through a period when prices are unrealistically high. Eventually, continued high prices result in some companies consistently making a loss and going out of business. Since many of the companies started at a similar time with a similar economic model, once one goes out of business many others follow. Essentially, the accrued wealth through the 'good' times enable companies to function for a certain period in an environment which is not economically sustainable. The buffer of the accrued wealth means that there is a delay between economically unsustainable conditions and the companies going out of business.

\subsubsection{Increasing Landfill Tax}

The typical effect of increasing Landfill Tax according to the historical time course (Figure 1), thereby increasing the cost of sending organic waste to landfill, is shown in Figure 3(a) and (b). At the start of the simulation, all organic waste goes to landfill. When the Landfill Tax is introduced and combined with the gate fee, it costs $£ 27$ / tonne for waste producers to send organic waste to landfill i.e. a 'price' of $-£ 27$ for organic waste. After three years, Landfill Tax is increased to $£ 10$, further increasing the cost of sending waste to landfill. This only leads to a small dip in the price of organic waste since, by this point, much of the waste is being recycled. As more and more organic waste is recycled, the price of 
organic waste becomes less and less sensitive to the Landfill Tax. Hence overall, the picture with gradually increasing Landfill Tax is qualitatively similar to that shown for no Landfill Tax in Figure 2. In the long term, the amount of waste going to landfill and the price for food waste are unchanged. This is because altering the Landfill Tax has only an indirect impact on the internal economics of the individual composters as it is a tax paid by the landfill operators. There is the same initial linear increase in the number of companies that is seen in the absence of Landfill Tax, but since the price remains attractive for longer, more companies start up.

There is an interesting side effect of the policy: as with no Landfill Tax, there are oscillations in the price that lead to oscillations in the number of composters and the amount of waste recycled. The Landfill Tax tends to exacerbate these oscillations, making their amplitude larger. This is because the Landfill Tax has a significant influence on the price for organic waste for the first few years. This is the period when most organic waste is still sent to landfill and there is little competition between waste processing companies. During this period, the price for organic waste is lower in the presence of Landfill Tax than in its absence. A lower price enables waste processing companies to make a higher profit. However, this higher profit means that they have more financial reserves, allowing them to remain in the market for longer when prices start to rise and resulting in prices reaching a greater maximum before crashing.

\subsubsection{Increasing ROCs}

The principle behind increasing Landfill Tax is that high gate fees will promote a market in biowaste around an equilibrium price. AD plants are more expensive to start up and more expensive to run than in-vessel composting. For this reason, our simulations of the effect of changing Landfill Tax did not lead to the development of an AD industry: competition between in-vessel composters kept the price that waste processors have to pay for waste above the level that makes AD plants economically viable. This position is changed with the introduction of ROCs, as is shown in Figure 3(c) and (d). In our simulations, ROCs at a fixed level equivalent to $8 \mathrm{p} / \mathrm{kWh}$ are introduced after six years, to mimic the introduction of ROCs in 2002, six years after the introduction of the Landfill Tax. 

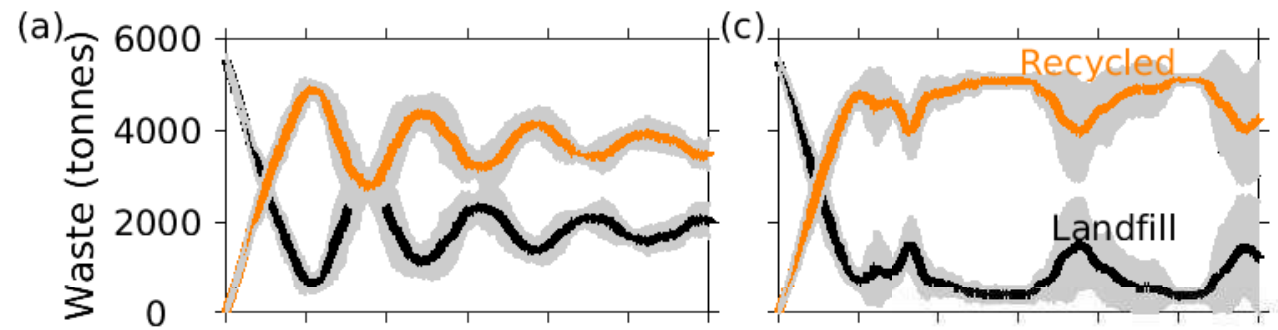

(b)
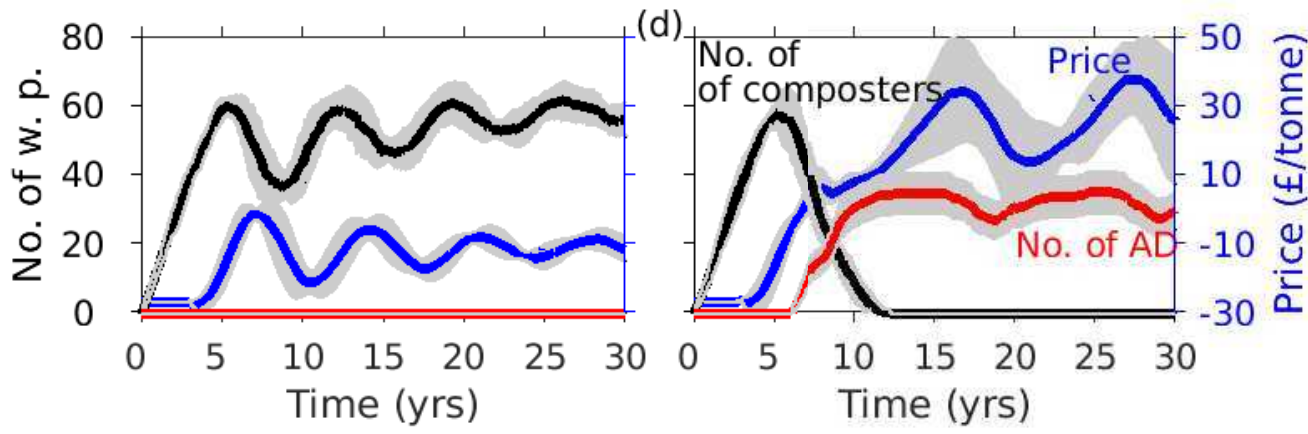

Figure 3: Typical model behaviour with Landfill Tax increased as shown in Figure 1 , where time zero corresponds to the time of the introduction of Landfill Tax in 1996. (a) and (b) in the absence of ROCs; (c) and (d) ROCs initially set at zero but increased to the fixed level of eight pence $/ \mathrm{kWh}$ of electricity after six years. The lines show: the amount of organic waste going to landfill (black); the amount of organic waste recycled (orange); the number of composters (black); the number of AD plants (red) and the price (blue). In all cases, the lines shown are the average for ten simulations. The grey band indicates the mean plus/minus one standard deviation to give an indication of the degree of variability between simulations.

Again, as waste processing businesses enter the marketplace, competition for waste drives the price up. The price reaches a high, unsustainable maximum before dropping and oscillating about an approximately constant level. During the first seven years, when there is ample waste and no ROCs incentive, composters start up. With the introduction of ROCs, AD plants also start to appear. However, once the price that waste processors have to pay for waste becomes unsustainably high because of the competition for waste, it is the companies who are 'fittest' that survive. Here, the fitness of the company depends crucially on the internal company finances with companies that are more profitable having more chance of survival. In the simulation shown in Figure 3(c) and $(\mathrm{d})$, the ROCs enable the AD plants to win out. 
The greater the financial incentive for anaerobic digestion, the more they dominate the marketplace, see Figure 4. This figure shows the results of four scenarios: in each case the Landfill Tax is ramped as shown in Figure 1 and ROCs are introduced after six years but at different levels $(4,6,8$, and 10p/KWh respectively). In panel (a), where ROCs are $4 \mathrm{p} / \mathrm{KWh}$, the ROCs level is too low for AD plants to start up, unlike in (b)-(d). The higher the ROCs level, the faster the development of the AD industry and the more quickly in-vessel composting collapses.

(a)
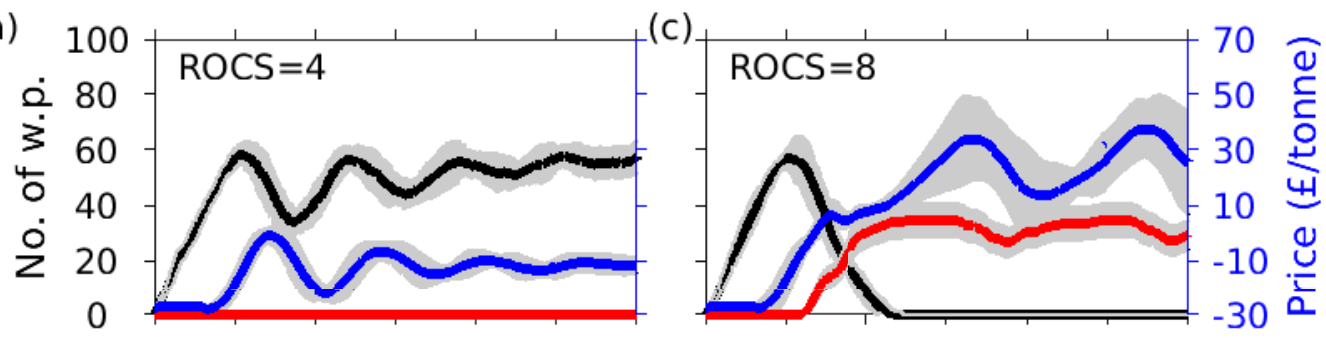

(b)

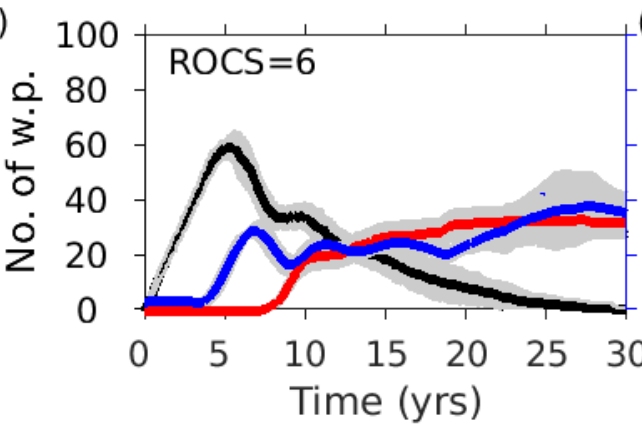

(d)

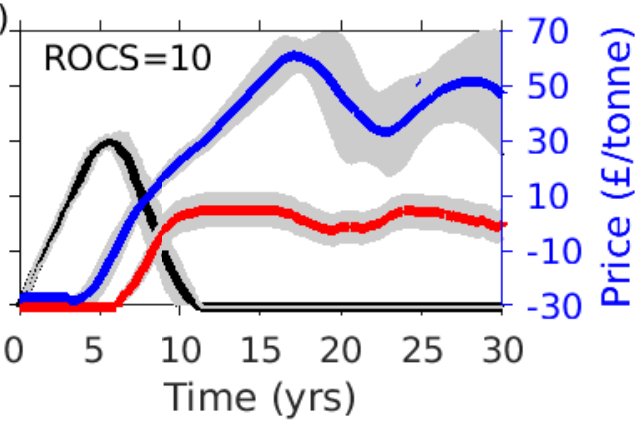

Figure 4: The impact of different levels of ROCs incentives. (a)-(d) show the dynamics in price (blue line), number of composters (black line) and AD plants (red line) for different levels of ROCs incentive. A ROCs level of $x$ means that $x$ pence $/ \mathrm{kWh}$ is paid for the electricity from year six onwards. A low level of ROCs, as in (a), means that it is not financially attractive for AD plants. Once ROCs levels are above a threshold to promote the growth of AD plants, the main impact of increasing ROCs is to push up the price of food waste.

Note that, once financial incentives are high enough that it becomes economically viable to run an AD plant, the overall level of the ROCs does little to directly benefit the waste industry: competition means that greater financial incentives result in higher prices for waste. So the main beneficiaries of financial incentives become the waste producers, not the waste processors. Consequently, 


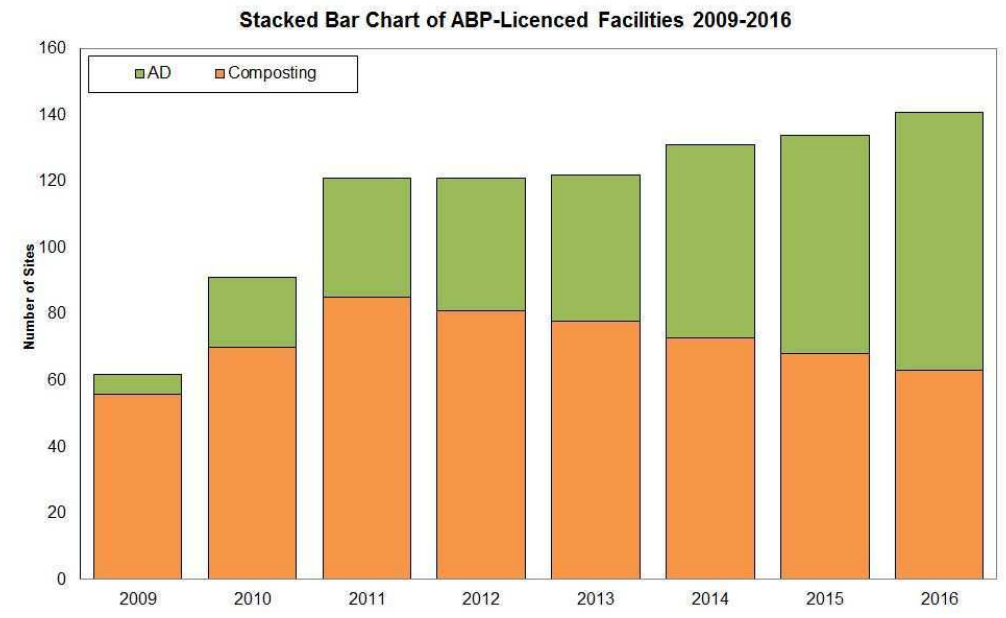

Figure 5: The number of AD plants and in-vessel composters in the UK for the period 2009-2016. Figure courtesy of Andrew Gadd, Link2Energy.

higher financial incentives do not result in more AD plants or in more waste being recycled and instead turns waste into a marketable by-product. This could be regarded as reducing the incentive to minimise waste generation, which runs counter to the fundamental principles of waste management.

To summarise, we can recognise that the drive to increase food waste recycling becomes a competition for the survival of the fittest between anaerobic digestion and in-vessel composting, where the 'fittest' is the type of business that is most economically profitable. This competitive scenario appears to be borne out by data on the number of AD plants and the number of in-vessel composters in the UK over the period 2009-2016, as shown in Figure 5. This suggests that AD plants are currently out-competing in-vessel composting. However, since the financial viability of anaerobic digestion is strongly tied to financial incentives determined by policy, this is not a robust situation. In the next section, we demonstrate that a phased removal/reduction of ROCs can lead to different scenarios. 


\subsection{Path dependency}

Figure 4 suggests that the relative composition of composters to anaerobic digesters depends on the financial incentives. However, the situation is more complex: the historical state of the market has a strong influence on policy outcome. This is illustrated in Figure 6(a) and (b). This shows the results of a series of simulations where the ROCs level is increased in increments of $1 \mathrm{p} / \mathrm{kWh}$ from zero up to $10 \mathrm{p} / \mathrm{KWh}$ and then reduced again. For each value of the ROCs, the simulations are run for 50 years so that transient behaviour has died away. This enables the underlying equilibrium structure to be determined. The timescales involved may mean that an equilibrium is never reached, but an understanding of the equilibrium structure is nevertheless useful: as we will see below, it is this equilibrium structure that underpins transient behaviour. So for the results shown in Figure 6(a) and (b) the sequence is: start at a ROCs level of zero, run the simulation for 50 years and record the outcome. Then increase the ROCs by $1 \mathrm{p} / \mathrm{kWh}$, and starting from the final state of the previous simulation, compute for a further 50 years and record the outcome. This is continued until the ROCs level is $10 \mathrm{p} / \mathrm{kWh}$. Then the process is repeated, but this time stepping down in ROCs. This whole process of increasing then decreasing the ROCs was repeated ten times. Figure (a) and (b) show the mean values, with error bars indicating the standard deviation across the ten different realisation. The filled/open circles correspond to values obtained for increasing/decreasing ROCs. The mean values are connected with a line to guide the eye.

In Figure 6 it can be seen that if the ROCs incentives are increased gradually from zero, no AD plants occur (cf Figure 4 (a)) until the ROCs level is above $5 \mathrm{p} / \mathrm{kWh} ;$ no composters occur if the ROCs levels are maintained above $7 \mathrm{p} / \mathrm{kWh}$ (cf Figure 4(c) and (d)). However, if the ROCs are first raised to a high level then reduced, a mixture of AD plants and composters can exist, even for ROCs levels below $5 \mathrm{p} / \mathrm{kWh}$. So for the same ROCs incentive (0 to $6 \mathrm{p} / \mathrm{kWh}$ ) the balance between the $\mathrm{AD}$ plants and composters is strongly dependent on the policy history. The reason for the existence of two possible outcomes for the same ROCs incentive is that the financial decision to start an AD plant is based on whether it is 'profitable' to do so. The decision on profitability is based on the current market price for organic waste, the cost of any other raw materials, the cost of any loans and the day-to-day running of the plant and the income from selling electricity, all assuming the plant is operating at $80 \%$ 
capacity. The conditions for company start-up are more stringent than those for an established AD plant to survive, since the established plants may be able to operate at greater than $80 \%$ capacity and/or have paid off their loans. So on gradually increasing the ROCs, no AD plants start up until the ROCs level is above approximately $5 \mathrm{p} / \mathrm{kWh}$. However, on decreasing the ROCs, it is possible for some AD plants to survive at ROCs levels below $5 \mathrm{p} / \mathrm{kWh}$. No account of future market price/policy expectations are made in the decision to start up, but including market expectations is unlikely to change the fact that the market conditions required for a company to start-up are unlikely to be the same as the market conditions required for a mature company to survive.
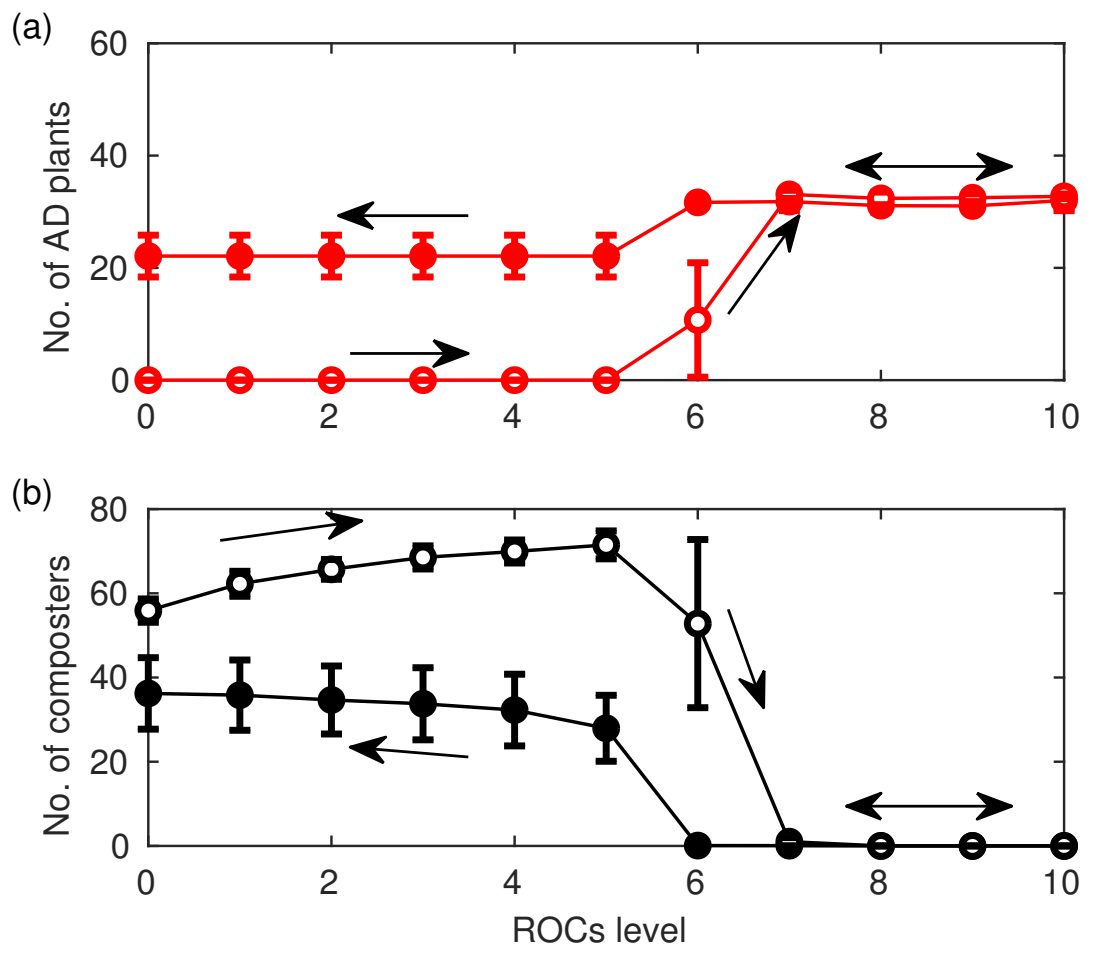

Figure 6: Path dependency: (a) and (b) show the steady-state number of AD plants and composters as ROCs are gradually increased from 0 to $10 \mathrm{p} / \mathrm{kWh}$ in steps of $1 \mathrm{p} / \mathrm{kWh}$, allowing sufficient time at each new ROCs value for transient behaviour to die away. The mean of ten different simulations is shown by the filled/open circles, corresponding to increasing/decreasing ROCs respectively. The error bars indicate the standard deviation across the ten different realisation. 
If the desired policy outcome is to have a sustainable AD industry but with minimal financial incentive, this suggests that this is possible, but only if there is sufficient investment for a long enough initial period to firmly establish the AD industry. This is further illustrated in Figure 7(a) and (b) where ROCs are introduced at a high level, then reduced after 10 or 30 years respectively. In each case, it appears that a thriving AD industry has been established between year 7 and year 17 when the higher level of incentives is in place. However, with the removal of the incentives in year 17 (Figure $7(\mathrm{a})$ ), the AD industry collapses because they are no longer financially viable. The crash in the AD industry results in a crash in prices with more waste initially diverted to landfill, before the in-vessel composting industry fills the vacuum. The difference after 30 years is that at least some of the AD plants have existed for long enough to pay off their set-up costs and/or are managing to operate at greater than $80 \%$ capacity - in the simulations it is assumed that loans to cover set-up costs are repaid over a twenty year period.

The wider implication is that a fixed low level of financial incentive may not be enough to kick-start the development of a given industry: the financial incentive needs to be high enough for investors to see a viable business plan, and in place long enough that businesses are firmly established and able to compete with other industries that use the same resources.

\section{Discussion}

Policy design is challenging: almost inevitably policies that are designed to have one primary effect have secondary, perhaps unintended, consequences. Here, our purpose is to illustrate the benefits of using an ABM as a thinking/scenario planning tool to aid the development of intuition [18]. Specifically, we consider how the interaction between in-vessel composting, a low-cost technology (that still demands considerable process control for quality output), and anaerobic digestion, could result in a market for organic waste.

The model shows that, as is to be expected in a market driven system, when resources are abundant prices are low. As they become scarcer, prices increase and reach a dynamic equilibrium value that is based on the need for companies to make a profit to survive and, consequently, on the financial incentives 

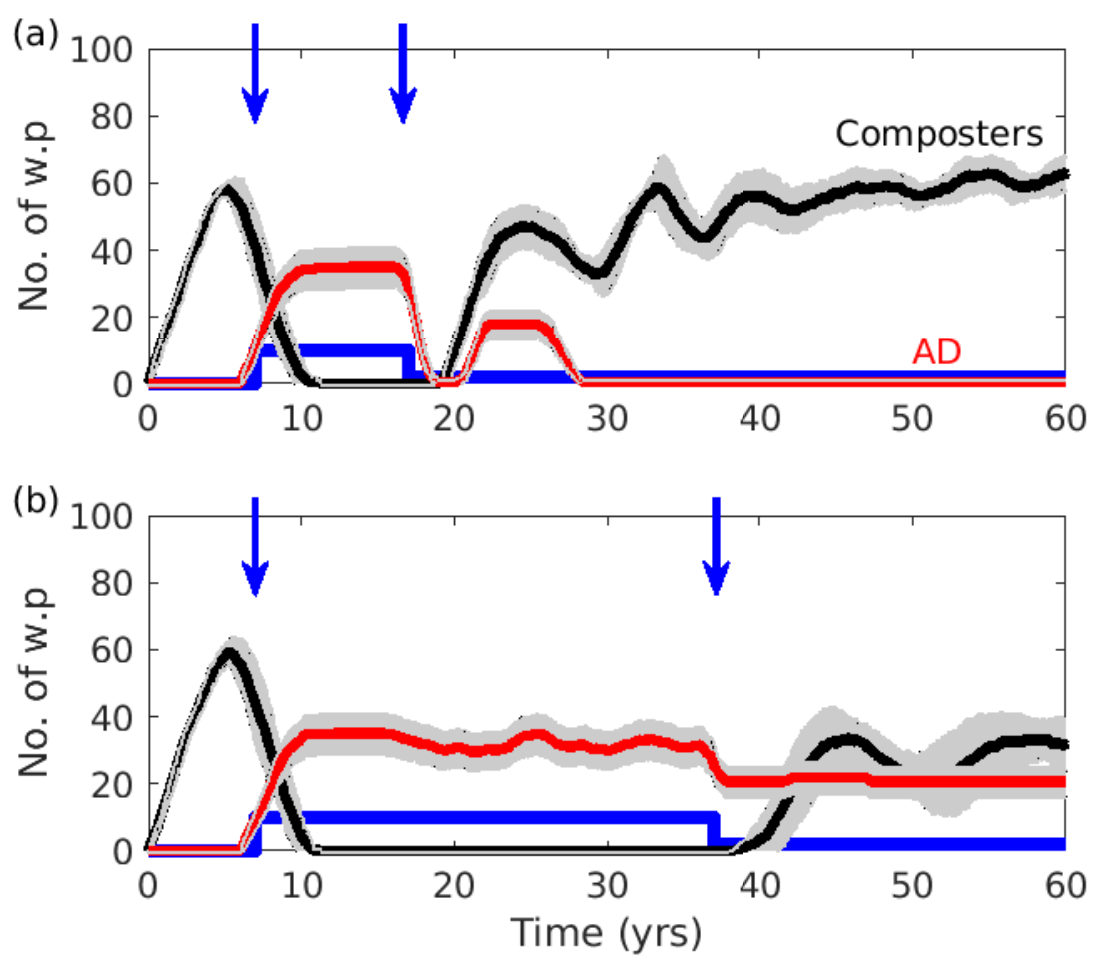

Figure 7: Path dependency: the effect of increasing ROCs after year 6 to 10 $\mathrm{p} / \mathrm{kWh}$ for a period of (a) 10 and (b) 30 years respectively, before reducing them to two pence/kWh. The mean number of composters (black) and number of AD plants (red) for ten different simulations. The grey band indicates the mean $+/-$ one standard deviation to give some idea of the variability across simulations. The ROCs level is shown in blue, with the blue arrows indicating the points where the ROCs levels are changed.

available in the system. However, the power of an ABM approach is both the ability to encode decisions at the microscale from which macroscopic patterns of behaviour emerge, and the ability to study the non-equilibrium situation. So, from the microscale of individual waste contracts between waste producers and waste processors emerges a pattern that suggests organic waste recycling could be viewed as a battle for the 'survival of the fittest' with AD plants and in-vessel composters competing for a finite resource (organic waste). Policies that give financial incentives can change the 'fitness' of different 'species' of company, with large financial incentives for some companies resulting in their market dominance. The need to study the non-equilibrium system is empha- 
sised by the decade long timescales required to reach equilibrium, when policy change typically occurs on the timescale of years.

Our results suggest that there are at least three possible indirect effects of the ROCs policy on the organic waste industry: firstly, by promoting AD plants as a means to recycle organic waste it could drive in-vessel composters out of business. Secondly, above a threshold level that is needed to make AD plants viable, increasing ROCs does little to promote AD and instead drives the price of organic waste up, effectively subsidising waste producers. The fact that financial incentives do not necessarily benefit those that they are aimed at is seen in other areas of policy, where, for example, financial incentives to help people buy houses can drive house prices up, not make houses more affordable. Thirdly, high levels of ROCs could result in the price of organic waste becoming positive, meaning that waste producers can sell their waste instead of having to pay for it to be removed. This potentially incentivises waste production rather than waste minimization. Hence the BEIS policy of ROCs could inadvertently undermine DEFRA's drive to reduce organic waste. This is a direct result of the differential impact of the ROCs policy on composters and AD plants because of the dual role that AD plants have as both waste treatment and energy production plants.

It appears that the Landfill Tax provides a useful driver to encourage waste processing companies to enter the marketplace, but once there is competition for waste, further increases in Landfill Tax may have little effect.

The discipline of developing an ABM can itself help clarify relationships and identify dominant factors/interactions that determine behaviour. Furthermore, although it may be difficult to find parameters to calibrate the model precisely, the modelling approach means that model outcomes can be tested as to their sensitivity to model assumptions. Like micro-economic simulations, our ABM simulation and analysis focuses on prices and tonnage and subsequent dynamics, although it could readily be extended to include other effects.

Finally, our results illustrate that different policy trajectories can lead to different business outcomes, as seen by our results on path dependency. Both the simulations shown in Figure 7 started with the same initial market state with all waste going to landfill and price dictated by the Landfill Tax. In both cases the ROCs level was introduced after six years at the level of $10 \mathrm{p} / \mathrm{kWh}$ 
and at the end of the simulation was at the level of $2 \mathrm{p} / \mathrm{kWh}$. In both cases a thriving AD industry appeared to have been established, but in one case the $\mathrm{AD}$ industry crashed, and in the other it did not. The difference between the simulations was the policy path: in one case ROCs were reduced after 30 years, and in the other after only 10 years. This illustrates the risks of stopping a costly policy when it appears to have 'worked'. This path dependency is typical of systems which are nonlinear, but is perhaps alarming from a policy design perspective: it confirms the fact that policies need to be well-designed to avoid lock-in to inferior outcomes.

Our results further highlight the fact that a static view of policy, with a given policy linked to a given outcome is insufficient to predict policy effect reinforces and the need for dynamic techniques such as agent-based modelling.

\section{Acknowledgements}

The authors thank: Lauren Basson for originally suggesting biowaste as a relevant policy area; Chris Knight for help with translating Netlogo code to MATLAB; Andrew Gadd and Malcolm Bailey from Link2Energy for useful discussions about the biowaste industry and for providing us with Figure 5. The support of the UK Engineering and Physical Sciences Research Council for programme grant EP/H021450/1 (Evolution and Resilience of Industrial Ecosystems, ERIE) and of the UK Economic and Social Rsearch Council Centre for the Evaluation of Complexity Across the Nexus (CECAN), grant ES/N012550/1 is gratefully acknowledged.

The authors confirm that the computational data underlying the findings are available without restriction. Details of the data and how to request access are available from the University of Surrey publications repository: DOI to be added. 


\section{References}

[1] Paul-Marie Boulanger and Thierry Brechet. Models for policy-making in sustainable development: The state of the art and perspectives for research. Ecological Economics, 55(3):337-350, November 2005.

[2] Andreas Pyka and Giorgio Fagiolo. Agent-Based Modelling: A Methodology for Neo-Schumpeterian Economics. Technical report, Augsburg Universität, Institute for Economics, 2005.

[3] Joshua M. Epstein and Robert L. Axtell. Growing Artificial Societies Social Science from the Bottom Up. MIT Press, Washington, DC, USA, 1996.

[4] Nigel Gilbert. Agent-Based Models. Number 153 in Quantitative Applications in the Social Science. SAGE Publications, 2008.

[5] H. David and G. Fagiolo. Agent-based models for economic policy design: Introduction to the special issue. Journal of Economic Behaviour and Organization, 67:351-354, 2008.

[6] Amineh Ghorbani, Francien Dechesne, Virginia Dignum, and Catholijn Jonker. Enhancing ABM into an inevitable tool for policy analysis. Policy and Complex Systems, 1(1):61-76, 2014.

[7] Natalia Zglobisz, Arturo Castillo-Castillo, Sue Grimes, and Peter Jones. Influence of UK energy policy on the deployment of anaerobic digestion. Energy Policy, 38 (10):5988-5999, 2010.

[8] Anaerobic digestion strategy and action plan. Technical report, 2011.

[9] Adam D. Read. Making waste work: making UK national solid waste strategy work at the local scale. Resources, Conservation and Recycling, 26:259-285, 1999.

[10] Department of the Environment. Making waste work: a strategy for sustainable waste management in England and Wales. 1995.

[11] Council directive 1999/31/EC of 26 April 1999 on the landfill of waste. Official Journal of the European Communities L182, 42 (16) (July):119, 1999. 
[12] Alison Smith, Keith Brown, Steve Ogilvie, Kathryn Rushton, and Judith Bates. Waste management options and climate change. Technical Report Final Report ED21158R4.1, AEA Technology, 2001.

[13] Government review of waste policy in England 2011. Technical report, DEFRA, 2011.

[14] Climate change act 2008. Technical report, 2008.

[15] DECC. The UK renewable energy strategy 2009. Technical report, 2009.

[16] U Wilensky. Netlogo. Center for Connected Learning and Computer-Based Modeling, Northwestern University. Evanston, IL., 1999.

[17] Matlab and statistics toolbox release 2015a,. The MathWorks, Inc., Natick, Massachusetts, United States.

[18] Wolfram Elsner, Torsten Heinrich, and Henning Schwardt. The microeconomics of complex economies: evolutionary, institutional, neoclassical and complexity perspectives. Academic Press, 2014. 


\title{
Agent-based modelling to steer policy outcomes: a food waste recycling example Supplementary material: details of the agent-based model
}

\author{
A.C. Skeldon ${ }^{1 *}$, F. Schiller ${ }^{2}$, A. Yang ${ }^{3}$, \\ T. Balke-Visser ${ }^{4}$, A. Penn ${ }^{5}$, N. Gilbert ${ }^{5}$ \\ 1 Department of Mathematics, University of Surrey, Guildford, Surrey, GU2 7XH, \\ 2 Handyurbansolutions, Handyurbansolutions.com, Hanover, \\ 3 Department of Engineering Science, University of Oxford, Oxford, OX1 3PJ, \\ 4 Vanderlande Industries, 5466 RB Veghel, Netherlands, \\ ${ }^{5}$ Department of Sociology, University of Surrey, Guildford, Surrey, GU2 7XH. \\ * Corresponding author \\ May 8, 2018
}

\section{Model details}

At each time step the agents in the model undertake a series of tasks, as listed in Table 1.

Within the model, the main role of waste producers is to produce waste which they then transfer either to landfill or to waste processing companies. The role of waste processors is more complicated and we give further details on how they function in 1.1. In 1.2, the values used for model parameters are discussed. There are a number of key decision rules: how waste processing companies decide to start-up; who trades with whom; the pricing of waste, and how different policies are implemented. These are discussed in sections $1.3,1.4,1.5,1.6$, respectively. 


\subsection{Waste processing}

The material processing is modelled as an input-output process where each waste processing company takes inputs of up to four different types and produces up to four different types of output, as illustrated in Figure 1.

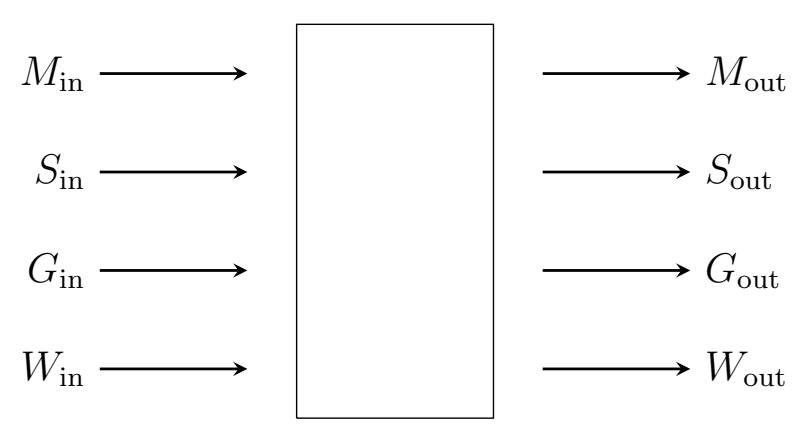

Figure 1: Process diagram for companies

Currently, these four different inputs/outputs represent: general material, $M_{i}$; food waste, $S_{i}$; carbon dioxide, $G_{i}$ and other waste, $W_{i}$, where the subscripts $i=$ in and $i=$ out are self-explanatory. The mapping between the inputs and the outputs is represented by a four by four 'process' matrix, $\mathbf{P}$ so

$$
\left(\begin{array}{c}
M_{\text {out }} \\
S_{\text {out }} \\
G_{\text {out }} \\
W_{\text {out }}
\end{array}\right)=\mathbf{P}\left(\begin{array}{c}
M_{\text {in }} \\
S_{\text {in }} \\
G_{\text {in }} \\
W_{\text {in }}
\end{array}\right) .
$$

This general structure is flexible in that the inputs/outputs could be re-labelled to represent different categories, as long as an appropriate process matrix $\mathbf{P}$ can be constructed. In the two particular cases considered here, $\mathbf{P}$ takes a particularly simple structure, but the model is designed to be readily extendable to more complex processes.

Composters take in food waste $\left(S_{\text {in }}\right)$, and produce compost $\left(M_{\text {out }}\right)$, and $\mathrm{CO} 2\left(G_{\text {out }}\right)$. Based on [1], these are taken to be related by $M_{\text {out }}=0.55 S_{\text {in }}$ 
and $G_{\text {out }}=0.324 S_{\text {in }}$ and the process matrix therefore takes the form

$$
\mathbf{P}=\left(\begin{array}{ccccc}
0 & 0.55 & 0 & 0 & 0 \\
0 & 0 & 0 & 0 & 0 \\
0 & 0.324 & 0 & 0 & 0 \\
0 & 0 & 0 & 0 & 0
\end{array}\right)
$$

$\mathrm{AD}$ plants take in food waste and produces digestate and biogas consisting mainly of methane and carbon dioxide. It is assumed that the biogas is then used to generate electricity. So the AD plant takes in food waste $\left(S_{\text {in }}\right)$ and produces $M_{\text {out }}$ consisting of digestate, electricity and CO2 $\left(G_{\text {out }}\right)$. CO2 is related to input waste by $G_{\text {out }}=0.74 S_{\text {in }}$.

To reflect that $M_{\text {out }}$ represents a mixture of digestate and electricity in the process matrix we have set that each tonne of food in produces one "unit" of $M_{\text {out }}$, where one unit of $M_{\text {out }}$ corresponds to 0.55 tonnes of digestate and $0.96 \mathrm{kWh}$. This fact that $M_{\text {out }}$ consists of two different types of output is then taken care of in the pricing of $M_{\text {out }}$, discussed further below.

$$
\mathbf{P}=\left(\begin{array}{ccccc}
0 & 1 & 0 & 0 & 0 \\
0 & 0 & 0 & 0 & 0 \\
0 & 0.74 & 0 & 0 & 0 \\
0 & 0 & 0 & 0 & 0
\end{array}\right)
$$

\subsubsection{Finances of waste processors}

At each time step, waste processors receive/pay money for their inputs, receive money for their outputs and pay operating costs. They may also have to make payments associated with loans. Since it can be expensive to set up a waste processing plant, particularly in the case of AD plants we assume that in order to start-up, waste processors have to take out a loan. Suppose that the price/tonne for each input/output is given by $£ P_{i}$ where $i=\left\{M_{\text {in }}, S_{\text {in }}, G_{\text {in }}, W_{\text {in }}, M_{\text {out }}, S_{\text {out }}, G_{\text {out }}, W_{\text {out }}\right\}$; that the size of a given company is $Z$ tonnes/day and they operate at a fraction $\alpha$ of their capacity, where $\alpha \in[0,1]$. Set-up costs are typically assumed to scale in according to a power law with size, we therefore suppose and is given by $£ L\left(Z / Z_{\text {ref }}\right)^{0.6}$, where $Z_{\text {ref }}$ is the size of a reference plant and $L$ is the cost of setting up a plant of size $Z_{\text {ref }}[2]$.

We assume that the loan is to be paid off at an annual interest rate of $100 r \%$ over a period of $n$ years. Suppose that their daily operating costs are proportional to size and given by $£ O_{c} Z$. Then the profit, $£ F$, for each day is given by

$$
F=\alpha Z\left[\left(P_{M_{\text {out }}} M_{\text {out }}+P_{S_{\text {out }}} S_{\text {out }}+P_{G_{\text {out }}} G_{\text {out }}+P_{W_{\text {out }}} W_{\text {out }}\right)\right.
$$




$$
\begin{aligned}
& \left.-\left(P_{M_{\mathrm{in}}} M_{\mathrm{in}}+P_{S_{\mathrm{in}}} S_{\mathrm{in}}+P_{G_{\mathrm{in}}} G_{\mathrm{in}}+P_{W_{\mathrm{in}}} W_{\mathrm{in}}\right)\right] \\
& -O_{c} Z-\frac{1}{365}\left(\frac{r L\left(\frac{Z}{Z_{r e f}}\right)^{0.6}}{1-(1+r)^{-n}}\right)
\end{aligned}
$$

Note that the prices $P_{i}$ can be positive or negative.

Current legislation does not charge for greenhouse gas emissions from composting or from $\mathrm{AD}$, and so at present, $P_{G_{\text {out }}}=0$.

Using the appropriate values from the processing matrix $\mathbf{P}$, for composters, equation (2) reduces to

$$
F_{C}=\alpha Z\left[0.55 P_{M_{\text {out }}}-P_{S_{\text {in }}}\right]-O_{c} Z-\frac{1}{365}\left(\frac{r L\left(\frac{Z}{Z_{\text {ref }}}\right)^{0.6}}{1-(1+r)^{-n}}\right)
$$

and for $\mathrm{AD}$ plants equation (2) reduces to

$$
F_{A D}=\alpha Z\left[P_{M_{\text {out }}}-P_{S_{\text {in }}}\right]-O_{c} Z-\frac{1}{365}\left(\frac{r L\left(\frac{Z}{Z_{r e f}}\right)^{0.6}}{1-(1+r)^{-n}}\right) .
$$

\subsection{Parameters}

An important element of any modelling endeavour, and agent-based modelling is no exception, is in choosing appropriate magnitudes for the many parameters.

\subsubsection{Company sizes}

UK food waste amounts to approximately 15 million tonnes a year, of which approximately 7.2 million is from households and 3.9 million from manufacturing from around 7000 food and drink companies. In 2009, there were 600,000 tonnes of food waste from the hospitality sector, most of which went to landfill.

For the simulations here, we consider only the largest 700 companies that together have a total waste output of approximately 2 million tonnes per annum. The average waste per day per company is 7.8 tonnes, with companies varying from 1 to 14.6 tonnes a day.

Anaerobic digesters can operate on a small scale, with some viable plants operating on farms primarily fed with slurry. Here we focus on the role of large commercial plants for food waste that can process about 50,000 tonnes of food waste/annum, equating to approximately 150 tonnes/day. 
In-vessel composters range from 10,000 tonnes/annum to 75,000

tonnes/annum, that is from 30 to 200 tonnes/day. In the model, the size of composters is set randomly between 30 and 200 tonnes/day.

\subsubsection{Parameters for loans}

It has been assumed that all loans have an interest rate of $5 \%$ and last for 20 years.

\subsubsection{Parameters for AD plants}

For AD plants, it is assumed that each tonne of waste, input results in $M_{\text {out }}$ consisting of 0.55 tonnes of digestate and $960 \mathrm{kWh}$ of electricity. with a price given by

$$
P_{M_{\text {out }}}=960 \times \text { Price } / \mathrm{kWh} \text { of electricity }+0.55 \times \text { price } / \text { tonne of digestate } .
$$

There is little market for digestate, so for the current simulations the price for digestate is set at $£ 0 /$ tonne.

Operating costs are set to be $£ 20 /$ tonne capacity each day this is based on the fact that a typical AD plant employs approximately 0.05 people per tonne each day.

In a report by Andersons on the economic viability of $\mathrm{AD}[3]$, it is estimated that to build an AD plant costs between $£ 2,500$ and $£ 6,000$ for every $\mathrm{kW}$ of electricity of generating capacity, averaging about $£ 4,000$. Since we assume a fixed size of AD plant with a generating capacity of $6 \mathrm{MW}$, we therefore choose $Z=Z_{\text {ref }}$ and $L=£ 24$ million.

\subsubsection{Parameters for composters}

The financial investment required to start composting is substantially lower than for $\mathrm{AD}$ and we have taken the cost for a reference plant that can take 1 tonne of waste a day as $L=£ 5000$. The operating costs are also lower and have been taken as $O_{c}=£ 10 /$ tonne of capacity. Like digestate, there is currently little market for compost from in-vessel composting, so the price for compost is set at $£ 0 /$ tonne.

\subsection{Waste processing company start-up}

In most of the simulations presented in this paper we assume that initially there are no waste processing companies and that all food waste goes to landfill, reflecting the position in the early 1990s when very little food 


\begin{tabular}{|l|l|c|c|}
\hline Agent & Parameter meaning & Parameter label & Value \\
\hline Waste producers & Size & & $1-14.6$ tonnes/day \\
\hline Anaerobic digester & Size & $Z$ & 150 tonnes/day \\
& Price of food waste & $P_{S_{i n}}$ & $*$ \\
& Price of product & $P_{M_{\text {out }}}($ digestate $)$ & $£ 0 /$ tonne \\
& & $P_{M_{\text {out }}}($ electricity $)$ & $£ 0.00-0.14 / \mathrm{kWh}^{\dagger}$ \\
& Size of initial loan & $L\left(Z / Z_{\text {ref }}\right)$ & $£ 24,000,000$ \\
& Interest rate & $r$ & $0.05(5 \%)$ \\
& Length of loan & $n$ & 20 years \\
& Operating costs & $O_{c} Z$ & $£ 20 \mathrm{Z}$ \\
\hline Composter & Size & $Z$ & $30-200$ tonnes/day \\
& Price of food waste & $P_{S_{\text {in }}}$ & $*$ \\
& Price of product & $P_{M_{\text {out }}}$ & $£ 0$ \\
& Size of initial loan & $L\left(Z / Z_{\text {ref }}\right)^{0.6}$ & $£ 5,000-120,000$ \\
& Cost of reference plant & $L$ & $£ 5000$ \\
& Size of reference plant & $Z_{\text {ref }}$ & 1 tonnes/day \\
& Interest rate & $r$ & $0.05(5 \%)$ \\
& Length of loan & $n$ & 20 years \\
& Operating costs & $O_{c} Z$ & $£ 10 \mathrm{Z}$ \\
\hline
\end{tabular}

Table S1: ${ }^{*}$ These are updated as the model runs. ${ }^{\dagger}$ This value depends on the ROCs. 
waste was recycled. At any given point in time, waste companies start up depending on whether (i) there is sufficient food waste going to landfill (ii) it is financially attractive to do so. Financial attractiveness is determined by using current market conditions in the model to estimate whether or not a composting/AD business will be profitable within five years, taking into account set-up costs, operating costs and predicted operating capacity. Composting requires relatively little investment to set up, is cheap to run and hence has little associated financial risk. In contrast, AD plants are expensive to set up and more labour intensive to run. This disparity in business types means that the financial conditions for the start up of $\mathrm{AD}$ plants are more stringent than for composters.

\subsection{Who trades with whom?}

Waste producing and waste processing agents interact with each other through two networks of links, one representing who knows who, 'contacts', and one representing the transfer of food waste from producer to processor as part of a waste 'contract'. These two networks are dynamic: new companies start with few contacts and, over time, gradually make contacts with other companies. This knowledge network is important because a necessary pre-condition for establishing a contract between companies is that companies know about each other. At an extreme, a lack of connectedness results in companies establishing an insufficient volume of contracts and business failure.

The choice of contract partner is based on who is in the waste processors contact network and who has waste to dispose of. If there is more than one possible waste supplier, then a contract is formed with the supplier of waste who is offering food waste at the lowest price. Since arranging contracts takes time, each day a fixed maximum number of contracts can be formed by any one processor.

Each waste processing company has a maximum possible operating capacity. Contracts are formed for a variable amount of time, dependent on whether the contract is with an AD plant or a composter. This reflects differences between the different business types: composters have considerable flexibility about when and how much waste they can take in and tend to operate on a daily basis. In contrast, AD plants have a less flexible operation, and will tend to have a mixture of short and some longer contracts. Consequently, in the ABM all contracts for composters are set to be fourteen days long. Each contract with and AD plant has a different length, chosen randomly from two weeks to six months. 


\subsection{Cost of waste}

In order to send waste to landfill, food waste producers have to pay landfill operators a fee that is dependent on the weight of food waste passing through the gate of the landfill site, the 'gate fee'. It is assumed that food waste producers will preferentially send their food waste to any company that will charge them less - or even pay them - for their waste.

Consequently, initially, when there are no food waste processors and all waste goes to landfill, the 'price' of waste is negative and is specified relative to the Landfill Tax, with an assumption that the gate fee for landfill sites is $£ 20$ more per tonne than the Landfill Tax: this is representative of gate fees for the period 2008-2014, as reported in [4] from data in [5]. Over time, as companies that process waste enter the market place, competition for food waste drives the average price up. This increase in waste food price happens at the agent level: it is assumed that food waste producers will increase the price of waste if they can send all of it to food waste processors, and decrease it if they have to send some waste to landfill, with the minimum price level being the gate fee.

\subsection{Policy implementation}

Two specific policy categories were discussed in Section 3, namely Landfill Tax and financial incentives for AD plants in the form of ROCs.

\subsubsection{Landfill Tax}

Landfill Tax is paid by landfill site operators to HM Customs and Revenue on the waste they collect. Landfill site operators pass on any change in Landfill Tax to their customers, so there is a direct correspondence between increases in Landfill Tax and increases in gate fee. Consequently, changes in Landfill Tax are modelled as changes in the cost of sending food waste to landfill sites.

\subsubsection{ROCs}

AD plants benefit from the RO policy through the biogas that they produce. This benefit is either in the form of a guaranteed payment based on the price per MWh of green electricity generated or from the market price of biogas. In the model, for simplicity, we assume that all AD plants use the biogas that they produce to generate electricity and receive a price for the electricity that is directly dependent on the ROCs they receive. 


\section{References}

[1] J.D. Murphy and N.M. Power. A technical, economic and environmental comparison of composting and anaerobic digestion of biodegradable municipal waste. Journal of Environmental Science and Health, Part A: Toxic/Hazardous Substances and Environmental Engineering, 41:865-879, 2006.

[2] A.M. Gerrard. Guide to Capital Cost Estimating. IChemE, 2001.

[3] Andersons. A detailed economic assessment of anaerobic digestion technology and its suitability to UK farming and waste systems. Technical report, 2010.

[4] Andrew Gadd and Gray Tennant. Gate fees show emerging trends. Technical report, 2014.

[5] WRAP. Gate fees report. Technical report, 2014. 